\title{
Sensorineural Hearing Loss in Chronic Kidney Disease Patients - A Major Concern
}

\author{
Abinaya Ravi ${ }^{1}$, Rock Britto Dharmaraj ${ }^{2}$, Neethu George ${ }^{3}$, Nishok Vijayakumar ${ }^{4}$, \\ Naveena Singaravel ${ }^{5}$, Nivetha Ravichandran 6 \\ 1, 2, 3, 4, 5, 6 Department of Community Medicine, Dhanalakshmi Srinivasan \\ Medical College Hospital, Perambalur, Tamilnadu, India.
}

Chronic kidney disease (CKD) is becoming a major health concern due to its increasing incidence among adults. There are few studies that suggest the possible relation between hearing loss and chronic kidney disease. So far only a small number of large population - based studies have assessed the relation between CKD and hearing loss. The global prevalence of CKD was 9.1\% (697.5 million cases) in 2017. The age and sex wise global prevalence of CKD was higher in women (9.5\%) than in men (7.3\%). In India, prevalence of sensorineural hearing loss (SNHL) is around 28 $\%$ to $77 \%$ among CKD patients. Studies found that the incidence was $77 \%$ for mild to very mild hearing loss and the incidence was $46 \%$ for moderate to severe hearing loss. Various theories behind SNHL in CKD patients are structural similarity between ear and kidney, increased blood viscosity because of hypertension and finally electrolyte imbalance which are all thought to play a role in development of SNHL in CKD patients. Major risk factors for SNHL in CKD patients are duration of CKD, hypertension, diabetes mellitus, serum urea and creatinine levels, electrolyte imbalance, packed cell volume (PCV), ototoxic drugs. CKD being a long-term illness and majority of cases of SNHL in CKD patients are permanent, it has a great negative impact on the patient's quality of life adding to the disability burden.
Corresponding Author: Dr. Abinaya Ravi, Jr Hostel, Dhanalakshmi Srinivasan Medical College and Hospital, Perambalur- 621212, Tamilnadu, India. E-mail:

abinayamuthukumaran91@gmail.com

DOI: $10.14260 / j e m d s / 2021 / 699$

How to Cite This Article:

Ravi A, Dharmaraj RB, George N, et al. Sensorineural hearing loss in chronic kidney disease patients - A major concern. J Evolution Med Dent Sci 2021;10(38):34543456, DOI: 10.14260/jemds/2021/699

Submission 09-07-2021,

Peer Review 30-08-2021,

Acceptance 06-09-2021,

Published 20-09-2021.

Copyright (C) 2021 Abinaya Ravi et al. This is an open access article distributed under Creative Commons Attribution License [Attribution 4.0 International (CC BY 4.0)] 


\section{BACKGROUND}

Chronic kidney disease is an increasing public health burden and a major sequela of many chronic diseases. There seems to be a considerable increase in the incidence of SNHL in CKD patients when compared to general population. Majority of those cases of SNHL go undiagnosed due to lack of awareness among patients. The relation between chronic kidney disease and hearing loss was reported first by Alport more than 80 years ago. ${ }^{1}$ SNHL is caused by damage to the structures in the inner ear or auditory nerve and affects high frequencies.

\section{Magnitude of the Problem}

With chronic kidney disease becoming a major health concern due to its increasing incidence among adults, there are few studies that suggest the possible relation between hearing and chronic kidney disease. ${ }^{2}$ Nevertheless, all the current evidences are obtained from small observational studies of CKD patients. So far only a small number of large population based studies have assessed the relation between CKD and hearing loss. CKD was independently associated with hearing loss in large community-based studies after adjusting for age, sex and other contributing factors in many studies. ${ }^{3}$ The global prevalence of CKD was $9.1 \%$ (697.5 million cases). The age wise global prevalence of CKD was higher in women $(9.5 \%)$ than in men (7.3\%). It was said nearly one third of all cases of CKD were in China and India. 10 countries had more than 10 million cases and 79 countries had more than 1 million cases. The overall age based global prevalence of CKD increased by $29.3 \%$ between 1990 and 2017. In India, the exact incidence of CKD in Indian population cannot be assessed accurately due to the absence of renal registry. ${ }^{4}$ Based on data from a population based study, it was found that prevalence of CKD is $785 \mathrm{pmp}$ (per million populations) and incidence of CKD is 160 pmp. ${ }^{5}$ Prevalence of sensorineural hearing loss is around $28 \%$ to $77 \%$ among CKD patients. Studies found that the incidence was $77 \%$ for mild to very mild hearing loss and the incidence was $46 \%$ for moderate to severe hearing loss. Audiometric studies showed that SNHL among CKD patients mainly affected high frequencies with a notch at $6 \mathrm{kHz}{ }^{6}$

\section{Risk Factors for SNHL in CKD Patients ${ }^{7}$}

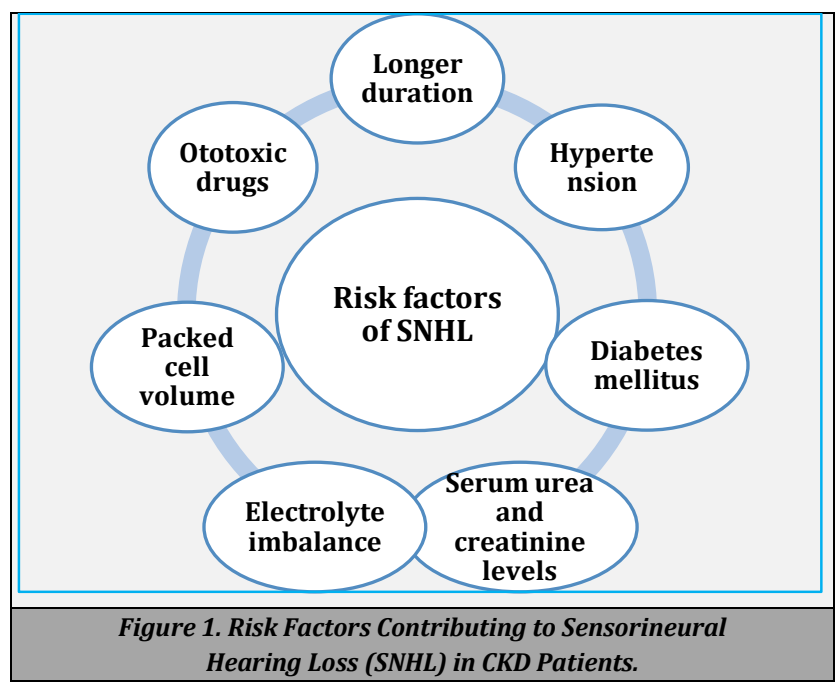

Theories on SNHL in Patients on Dialysis

There are various theories explaining the pathogenesis of SNHL in CKD patients. Of these, hypertension, electrolyte imbalance and anatomical and physiological similarities between renal tubal cells and the cochlear hair cells seems to be the most plausible explanations. Epithelial cells have microvilli containing numerous mitochondria and play an active role in the transport of fluid and electrolyses with the help of $\mathrm{Na}+-\mathrm{K}+$ ion pump and carbonic anhydrase enzyme. 8 Some studies have postulated that there was a correlation between hearing loss and electrolyte abnormalities in dialysis patients which was speculated to be linked to a malfunction of the ionic membrane transport. This leads to osmotic alteration that causes loss of cochlear hair cells and collapse of endolymphatic spaces with oedema and atrophy of specialized auditory cells. ${ }^{9}$

Hypertension is the main cause of chronic kidney disease. Studies show that high pressure in the vascular system causes increase in blood viscosity leading to reduction in the capillary blood flow and subsequent reduction in oxygen transport leading to cochlea hypoxia and loss of outer hair cells leading to sensorineural hearing loss. ${ }^{10}$ This study further showed that increased systolic blood pressure and diastolic blood pressure were significantly associated with hearing loss.

There are many similarities between renal tubular cells and stria vascularis of the cochlea. Both of these structures include epithelia in close contact with their vascular supply and the basement membrane. ${ }^{11}$

One study showed the relation of SNHL to peritoneal dialysis (PD) and haemodialysis (HD). It was found that patients of PD had significantly less SNHL when compared to patients on HD. This difference was correlated to serum urea levels of patients, showing that serum urea levels were lower in patients of PD compared to patients on HD. This held true for both pre dialysis and post dialysis serum urea levels. ${ }^{12}$

\section{Evaluation of Hearing Loss ${ }^{13}$}

\begin{tabular}{|cc|}
\hline WHO Classification & Hearing Loss (Decibel Range) \\
Mild & $26-40 \mathrm{~dB}$ \\
Moderate & $41-55 \mathrm{~dB}$ \\
Moderately severe & $56-71 \mathrm{~dB}$ \\
Severe & $71-91 \mathrm{~dB}$ \\
Profound & $>91 \mathrm{Db}$ \\
\hline Table 1. WHO Classification of Hearing Loss \\
\hline
\end{tabular}

\section{Clinical Tests}

1. Rinne's test: positive

2. Weber's test: lateralised to affected ear

The most commonly used methods in investigating the effects of kidney disease on the auditory system is pure-tone audiometry. Mild to moderate hearing loss is the most frequently encountered degree of hearing loss in patients with CKD whereas sensorineural hearing loss (SNHL) is the most commonly associated type of hearing loss in patients with CKD. ${ }^{14}$

\section{Recommendations}

- $\quad$ Since hypertension and diabetes remains one of the main causes of chronic kidney disease, proper control of the diseases with medications is essential.

- Judicious use of ototoxic drugs is advisable. 
- $\quad$ Screening of CKD in high-risk population (Endemic areas, family history, poor medication adherence etc.) helps in early diagnosis so that progression of disease and its consequences can be halted.

- $\quad$ CKD patients should be made aware of the possibility of SNHL and should be evaluated for hearing loss at 6 monthly intervals.

- Treating patients should refer all patients reporting hearing loss to an otolaryngologist for evaluation.

- The choice between peritoneal dialysis and haemodialysis should be made after considering the patient's level of hearing and audiometry values.

When hearing loss sets in, reassurance of the patient and providing appropriate aids helps in rehabilitation.

\section{CONCLUSIONS}

Given the high incidence and prevalence of CKD in India, SNHL is not a rare complication. However, many cases of SNHL in CKD patients may go undiagnosed. SNHL in CKD patients are often permanent, difficult to treat and have a great level of negative impact on the patient's quality of life.

So early diagnosis with regular check-up and prompt follow-up combined with rational management can greatly reduce the incidence of SNHL in CKD patients. It can even reduce the progression of SNHL in CKD patients

Financial or other competing interests: None.

Disclosure forms provided by the authors are available with the full text of this article at jemds.com.

\section{REFERENCES}

[1] Alport AC. Hereditary familial congenital haemorrhagic nephritis. Br Med J 1927;1(3454):504-6.
[2] Bazzi C, Venturini CT, Pagani C, et al. Hearing loss in short - and long - term haemodialysed patients. Nephrol Dial Transplant 1995;10(10):1865-8.

[3] Vilayur E, Gopinath B, Harris DC, et al. The association between reduced GFR and hearing loss: a cross - sectional population-based study. Am J Kidney Dis 2010;56(4):6619.

[4] Williams MA, Sklar AH, Burright RG, et al. Temporal effects of dialysis on cognitive functioning in patients with ESRD. Am J Kidney Dis 2004;43(4):705-11.

[5] Meena RS, Aseri Y, Singh BK, et al. Hearing loss in patients of chronic renal failure: a study of 100 cases. Indian J Otolaryngol Head Neck Surg 2012;64(4):356-9.

[6] Zeigelboim BS, Mangabeira - Albernaz PL, Fukuda Y. High frequency audiometry and chronic renal failure. Acta Otolaryngol 2001;121(2):245-8.

[7] Thodi C, Thodis E, Danielides V, et al. Hearing in renal failure. Nephrol Dial Transplant 2006;21(11):3023-30.

[8] Ohinata Y, Makimoto K, Kawakami M, et al. Blood viscosity and plasma viscosity in patients with sudden deafness. Acta Otolaryngol 1994;114(6):601-7.

[9] Egidio Jr. Chronic kidney disease-definition, epidemiology and classification. Braz J Nephrol 2004;26(3):1-3.

[10] Adler D, Fiehn W, Ritz E. Inhibition of $\mathrm{Na}+, \mathrm{K}+-$ stimulated ATPase in the cochlea of the guinea pig. A potential cause of disturbed inner ear function in terminal renal failure. Acta Otolaryngol 1980;90(1-2):55-60.

[11] Yassin A, Badry A, Fatt-Hi A. The relationship between electrolyte balance and cochlear disturbances in cases of renal failure. J Laryngol Otol 1970;84(4):429-35.

[12] Selby NM, McIntyre CW. The acute cardiac effects of dialysis. Semin Dial 2007;20(3):220-8.

[13] Olusanya BO, Davis AC, Hoffman HJ. Hearing loss grades and the International classification of functioning, disability and health. Bull World Health Organ 2019;97(10):725-8.

[14] Fidan V, Binici D, Borazan A. The prevalence of hearing loss in dialysis patients. Acta Acust United Acust 2012;98(1):800-3. 